\title{
Administration of ECT by trainee psychiatrists
}

\author{
An audit of supervision, adequacy of tuition and attitudes
}

\author{
Jonathan Hillam, Amanda Thompsell and Robert Tobiansky
}

\begin{abstract}
There has been Increasing concern in recent years that trainee poychlatists are not recelving adequate training and are not fully competent in the actministration of electroconvulatve therapy (ECD). This has led to the publication of guidelines by the Royal College of Pyychiatitsts recommending mecsures to improve supervition and tulition. This study compares the results of two survoys, five years apart, exploring lovels of supervision, saltistaction with troining and confidence in the procedure among trainee peychlatitits on the Royal Free Hospltal scheme. The findings are discussed in the light of improvements to teaching of ECT in the inferim. Continuing problems with supervibion are highilghted, and the need for organised training is emphasteed.
\end{abstract}

The use of electroconvulstve therapy (ECT) in England has declined steadily over many years (Pippard, 1992). Nevertheless, it is generally accepted to be an effective and still useful treatment for severe depression despite the introduction of better tolerated antidepressants. Any reduction in the prescribing of ECT, for whatever reason, has a number of important implications not only for the patient but also for the trainee psychiatrist. Reduced experience in administering ECT may be expected to result in lower expertise and confidence in giving the treatment effectively, and could lead to an inability to identify those cases most likely to benefit. Patients would be at risk of receiving suboptimal treatment, given by under-experienced practitioners, or from the use of out-dated techniques or equipment.

Formal teaching of the theory and practice of ECT is a necessary component of any psychiatric training scheme. Guidelines such as The Practical Administration of Electroconvulsive Therapy (Royal College of Psychiatrists, 1989) and more recently The ECT Handbook (Royal College of Psychiatrists, 1995) have represented important steps towards improving its practice. The standard of training and supervision of those giving the treatment has, however, remained unsatisfactory, as has competence in the technique
(Pippard, 1992; Henderson et al, 1993; Ramsay \& McPhillips, 1993).

In view of this concern it was decided to survey the experiences of the trainees currently on the psychiatric training scheme of the Royal Free and its associated hospitals, and to compare them with findings of a similar survey five years ago.

\section{The study}

The training scheme run by the Royal Free and associated hospitals provides psychiatric experience in a number of settings: district general hospital, inner-city psychiatric hospital, private hospital as well as the teaching hospital itself. There are a total of 46 senior house officers (SHOs) and Registrars. An induction course for new trainees has been run for a number of years, a component of which, for the last 4 years has been a seminar on the theory and practice of ECT. In addition, but indirectly, the MRCPsych course at the central site includes some teaching on the subject.

Each trainee was contacted by telephone by one of the authors (AT) and interviewed using a structured questionnaire. This aimed to determine the extent and adequacy of the individuals' supervision and of both theoretical and practical instruction. More subjective variables were also explored, namely confidence in giving ECT and any distress experienced. The questionnaire was designed to allow comparisons with the results of a previous survey of Royal Free trainees undertaken five years ago by one of the authors (RT). At that time, there was no formalised teaching of ECT.

Data analysis of the 1990 findings was carried out using the SPSS computerised program. Ordinal and binary variables were compared using the Mann-Whitney $U$ test and Spearman's rank correlation where appropriate. Comparisons of variables between surveys were carried out using $\chi^{2}$ tests where appropriate. 


\section{Findings}

The total number of questionnaires returned in 1990 was 51 from a total of 55 trainees. compared with 34 from 46 trainees in 1995. This represents a response rate of $93 \%$ and $74 \%$ respectively.

The 12 trainees who could not be contacted for the 1995 survey were representative of the rotation as a whole in terms of duration of training and current and previous posts held; hence we do not feel that this missing data represents a significant confounding factor. Duration of training of individuals questioned was similar between the two surveys as was the proportion having had experience of the procedure (see Table 1).

In the 1995 survey, all but six trainees - who had started on the rotation less than three months before the interview - had administered ECT, mostly within the last year and the majority report having given more than five treatments (Table 1). All had been supervised on the first occasion, although in most cases (54\%) this was by a fellow trainee; only one had observed, or had been supervised for, more than three treatments. This represents some improvement, however, as in $1990,16 \%$ were unsupervised on the first occasion, and a further $7 \%$ were supervised by the nurse or anaesthetist. This is reflected in the increased numbers of trainees reporting their practical instruction as at least adequate $(71 \% v$. 62\%); perceived adequacy of theoretical instruction also was higher in the 1995 sample, 75\% compared with $47 \%$ in $1990\left(\chi^{2}=15.2, P<0.001\right.$; Table 2).

Most trainees were confident in their ability to administer ECT (86\% in 1995 and $80 \%$ in 1990) but a substantial proportion (over one-fifth in both surveys) also admitted to distress or unease when giving ECT (Table 3). In the 1990 survey, confidence was associated with degree of supervision recelved (Mann-Whitney $U, P<0.05$ ), and inversely related to distress experienced (Spearman's $P<0.01$ ). Of the nine who reported distress in the 1995 survey, three felt the theoretical teaching was inadequate, and four stated that practical instruction was inadequate; three also admitted to lack of confidence in the procedure.

\section{Discussion}

This study had two main aims. The first was to identify current levels of supervision, adequacy of training, and trainees' attitudes and confidence in giving ECT. The second was to compare the present situation with that prevailing five years ago. Since then formal teaching sessions on the theory of ECT have been implemented as part of the trainees' induction course. This paper reports the findings of the completed audit cycle. The numbers involved are, however, relattvely small, so the statistical analyses should be considered accordingly.

There have been some apparent improvements in the training of ECT since the initial survey: at least according to the trainees themselves. Overall, a higher proportion had been supervised by a more senior doctor (i.e. senior registrar or consultant) and more reported that practical training was at least adequate; these differences reflect a trend but did not reach statistical significance. Trainees were more satisfied with the theoretical tuition received and there was a significant increase in levels of confidence. This was indeed high in both surveys but as Henderson et al (1993) have demonstrated, it is a poor indicator of actual competence. Evaluation of competence of administration of ECT was, however, outside the scope of this paper.

Such improvement as there has been may be explained by the establishment of formal teaching, raising awareness of the need for organised supervision, and for improved standards. Even

Table 1. Duration of training and experience of ECT

\begin{tabular}{lll}
\hline & $\begin{array}{l}1990(n=51) \\
n(\%)\end{array}$ & $\begin{array}{l}1995(n=34) \\
n(\%)\end{array}$ \\
\hline $\begin{array}{l}\text { Duration of psychiatric training } \\
<6 \text { months }\end{array}$ & $6(12)$ & $7(21)$ \\
6 months-1 year & $8(16)$ & $2(5.5)$ \\
$1-2$ years & $17(33)$ & $9(26.5)$ \\
$>2$ years & $20(39)$ & $16(47)$ \\
Experience of administering ECT & $\chi^{2} 3.39($ d.f.=3) & NS \\
Total number having experience & & $28(82)$ \\
Of these: & $50(98)$ & 3 \\
number having administered <5 treatments & - & $25(89)$ \\
number having administered 5+ treatments & - & $25(89)$ \\
number administered ECT last 12 months & - & \\
\hline
\end{tabular}


Table 2. Supervision and instruction recelved

\begin{tabular}{|c|c|c|}
\hline & $\begin{array}{l}1990(n=50) \\
n(\%)\end{array}$ & $\begin{array}{l}1995(n=28) \\
n(\%)\end{array}$ \\
\hline $\begin{array}{l}\text { Supervision recelved on first occasion } \\
\text { recelved some form of supervision } \\
\text { supervised by fellow SHO/registrar } \\
\text { supervised by senior registrar } \\
\text { supervised by consultant } \\
\text { other (nurse or anaesthetist) }\end{array}$ & $\begin{array}{l}43(86) \\
27(54) \\
6(12) \\
6(12) \\
4(8) \\
\chi^{2} 5.59(d . f .=3)\end{array}$ & $\begin{array}{l}28(100) \\
15(54) \\
9(32) \\
4(14) \\
0 \\
\text { NS }\end{array}$ \\
\hline $\begin{array}{l}\text { Theoretical instruction (excluding thos } \\
\text { very adequate/adequate } \\
\text { very inadequate/inadequate } \\
\text { unsure }\end{array}$ & $\begin{array}{l}23(46) \\
26(52) \\
1(2) \\
\chi^{2} 15.2(\text { d.f. }=2)\end{array}$ & $\begin{aligned} & 21(75) \\
& 3(11) \\
& 4(14) \\
& P<0.001\end{aligned}$ \\
\hline $\begin{array}{l}\text { Practical instruction (excluding those } \\
\text { very adequate } \\
\text { very inadequate/inadequate } \\
\text { unsure }\end{array}$ & $\begin{array}{l}31(62) \\
16(32) \\
3(6) \\
\chi^{2} 3.86(\text { d.f. }=2)\end{array}$ & $\begin{array}{l}20(71) \\
4(14) \\
4(14) \\
\text { NS }\end{array}$ \\
\hline & $\begin{array}{l}1990(n=50) \\
n(\%)\end{array}$ & $\begin{array}{l}1995(n=28) \\
n(\%)\end{array}$ \\
\hline $\begin{array}{l}\text { Confidence in administering ECT } \\
\text { very confident/confident } \\
\text { very unconfident/unconfident } \\
\text { unsure of competence }\end{array}$ & $\begin{array}{l}40(80) \\
1(2) \\
9(18) \\
\chi^{2} 12.16(\text { d.f. }=2)\end{array}$ & $\begin{array}{l}24(86) \\
4(4) \\
0 \\
P<0.01\end{array}$ \\
\hline 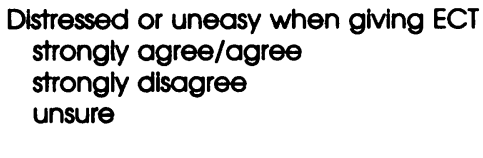 & $\begin{array}{l}15(30) \\
30(60) \\
5(10) \\
\chi^{2} 1.0(\text { d.f. }=2)\end{array}$ & $\begin{array}{l}6(21) \\
19(69) \\
3(11) \\
\text { NS }\end{array}$ \\
\hline
\end{tabular}

so, still too many trainees are being supervised by their peers rather than by more senior psychiatrists, and the extent of even this level of supervision is limited. This is in common with findings from other units and training rotations (Hill-Smith \& Lee, 1992; Ramsay \& McPhillips, 1993; Henderson et al, 1993) but, nevertheless, falls short of the recommendations of the Royal College of Psychiatrists (1989) that "All trainees should have the opportunity of seeing ECT administered on several occasions by an experienced operator". This phrase has not been retained in the latest College guidelines (1995); and, although recommendations for supervision have received greater emphasis, they remain sparse and open to interpretation.

If, as seems likely, degree of supervision as well as formal teaching has an effect on confidence and competence then it has important implications for the well-being of patients and the professional development of the trainee psychiatrist. The "see one, do one, teach one" culture in the Health Service as a whole is beginning to be replaced by more organised teaching. Formal and documented training in psychotherapy has been introduced into many training schemes and log-books are becoming commonplace. Proposals (Pippard, 1992) to adopt more rigorous tuition of ECT along American lines (American Psychiatric Association, 1990) should, therefore, be considered if the profession is to ensure that its most widely prescribed practical procedure is carried out effectively. On a local level we believe that audit of ECT practice, and particularly of the competence of those administering it, should be a priority of every mental health unit, as should regular and continuing supervision and tuition of trainees by an appropriate senior psychiatrist.

\section{Acknowledgement}

We thank Bob Blizard for his help and advice with the statistical analysis of the data from the 1990 survey. 


\section{References}

AMterican PSYchintric Association (1990) The Practice of Electroconuulsive Therapy. Recommendations for Treatment, Training and Privlleging. Washington, DC: APA.

Henderson, T., Anderson, M. J. \& Stark, C. R. (1993) Administration of electro-convulstve therapy: training. practice and attitudes. Psychiatric Bulletin. 17. 154 155.

HinL-SMrth, A. J. \& LEE, M. S. (1992) ECT-current practical administration. Psychiatric Bulletin, 16, 269271.

PIPPARD, J. (1992) Audit of electro-convulstve therapy in two national health service reglons, Brttish Joumal of Psychiatry, 160, 621-637.

Ramsay, N. \& MCPHIuIPS, M. A. (1993) Training and supervision of electro-convulstve therapy in a peychiatric training rotation. Psychiatric Bulletin. 17. 716-718.
RoYal College of Psychiatrists (1989) The Practical Administration of Electroconiulsive Therapy. London: Gaskell.

- (1995) The ECT Handbook. The Second Report of the Royal College of Psychiatrists' Special Committee on ECT. London: RCPsych.

-J. C. Hillam, Senior Registrar, Department of Psychiatry, Royal Free Hospital, Pond St, London NW3; A. Thompsell, Registrar, Department of Psychiatry, Royal Free Hospital; and R. I. Tobiansky, Consultant, Department of Old Age Psychiatry, Colindale Hospital, London NW9

*Correspondence

\section{Recent Council Reports}

CR47 College policy statement on rape, $£ 7.50$

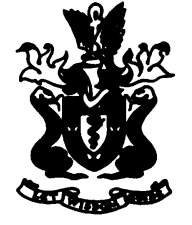

CR48 Report of the Working Party to review psychiatric practices and training in a multi-ethnic society, $£ 5.00$

CR49 Consensus statement on the assessment and investigation of an elderly person with suspected cognitive impairment by a specialist old age psychiatry service, $£ 5.50$

CR50 'Wish you were here'? Ethical considerations in the admission of patients to substandard psychiatric units, $£ 2.50$

CR51 The Responsiblities of Consultant Psychiatrists, $£ 5.00$

CR52 Sexual Abuse and Harassment in Psychiatric Settings, $£ 5.00$

CR53 Assessment and clinical management of risk of harm to other people, $£ 3.00$

CR54 Chronic fatigue syndrome, $£ 10.00$

Available from the Publications Department, Royal College of Psychiatrists, 17 Belgrave Square,

London SW1X 8PG (Tel. +44(0)171 235 2351, extension 146). The latest information on College publications is available on the INTERNET at: http://wrww.demon.co.uk/rcpsych/ 